\title{
KAJIAN KINETIKA PEMBUATAN EPIKLOROHIDRIN
}

\author{
Herliati ${ }^{11}$ \\ ${ }^{1)}$ Teknik Kimia Universitas Jayabaya Jakarta \\ herliati@ftijayabaya.ac.id
}

\begin{abstract}
Conventionally epichlorohydrin (EPCH) is made by dehydrochlorination of allyl chloride obtained from high-temperature chlorination of propylene. Unfortunately, the method produces a large amount of chlorinated by-products and consumes loads of energy due tohigh operating temperature. In this study, an alternative approach for the production of epichlorohydrin would be to use glycerol from biodiesel production plant. Epichlorohydrin is made by dehydrochlorination of 1,3-dichloropropanol (1,3-DCP) obtained from hydrochlorination of glycerol with aqueous hydrogen chloride. Experimental study on dehydrochlorination reaction was carried out under operating temperatures ranged from 50 to $80^{\circ} \mathrm{C}$ and reactant molar ratio from 1:5 (excess sodium hydroxide solution) during 10 minutes. The reaction kinetics conformed to pseudo first order with respect to dichloropropanol concentration. The activation energy of the reaction was determined at 38.8 $\mathrm{kJ} / \mathrm{mol}$ and the pre-exponential factor $A$ was at $1.62 \times 107 \mathrm{sec}^{-1}$. Quantitative analyses of the reaction products were performed using GC-MS (Gas Chromatography-MassSpectrometry).
\end{abstract}

Keywords: epichlorohydrin, dichloropropanol, hydrochlorination, Kinetics study, muriatic acid.

ABSTRAK. Secara konvensional, epiklorohidrin (EPCH) dihasilkan dengan proses dehidroklorinasi alil klorida, dimana diperoleh dari klorinasi propilen pada suhu tinggi. Sangat disayangkan, metode ini memiliki kelemahan yaitu menghasilkan hasil samping klorin dalam jumlah besar, membutuhkan energi yang besar karena beroperasi pada suhu tinggi dan menggunakan bahan baku tak terbarukan yaitu propilena. Kajian ini, merupakan sebuah alternatif dimana menggunakan bahan baku gliserol limbah dari produksi biodiesel. Epiklorohidrin diperoleh dengan dehidroklorinasi 1,3-dichloropropanol (1,3-DCP) yang diperoleh dari hidroklorinasi gliserol dengan liquid hidrogen klorida 37\%. Kajian kinetika pada reaksi dehidroklorinasi berlangsung pada kisaran suhu 50 to $80^{\circ} \mathrm{C}$ dan molar rasio $1: 5$ (sodium hidroksida berlebih) selama 10 menit. Hasil kinetika diperoleh orde reaksi adalah orde satu pseudo terhadap konsentrasi dikloropropanol. Energi aktivasi adalah $38.8 \mathrm{~kJ} / \mathrm{mol}$ dan faktor pre-exponensial $A$ adalah $1.62 \times 107 \mathrm{det}^{-1}$. Analisa kuantitatif hasil reaksi dilakukan dengan GC-MS GC-MS (Gas Chromatography-MassSpectrometry).

Kata Kunci: epiklorohidrin, dikloropropanol, hidroklorinasi, Studi kinetika, asam muriatik 


\section{PENDAHULUAN}

Epiklorohidrin, merupakan senyawa organoklorin dan epoksida, banyak digunakan sebagai bahan baku pembuatan epoksi, penoksi, resin-resin poli amida, karet poli eter, surfaktan, elastomer, pengemulsi minyak, lubrikan, dan cat. Selain itu, epiklorohidrin juga digunakan sebagai stabilizer pada senyawa-senyawa yang mengandung klorin seperti karet, pestisida, dan solven (Bijsterbosch dkk, 1994). Menurut (Nagato dkk, 1987), secara konvensional, epiklorohidrin disintesa dengan dehidroklorinasi alil klorida, yang diperoleh dengan klorinasi propilen pada suhu tinggi. Sayangnya, metode ini memiliki beberapa kelemahan seperti pembentukan hasil samping klorin dalam jumlah besar dan konsumsi energi yang tinggi karena reaksi berlangsung pada suhu tinggi, hal ini diperkuat dengan pendapat dari (Siano dkk, 2006). Saat ini, gliserol sebagai hasil samping produksi biodiesel tersedia melimpah, hal ini memberikan peluang untuk sintesa epiklorohidrin dari gliserol dengan menambahkan sejumlah larutan basa. Sintesa epiklorohidrin dari gliserol melalui dua tahap reaksi (Santasesari. dkk, 2010)

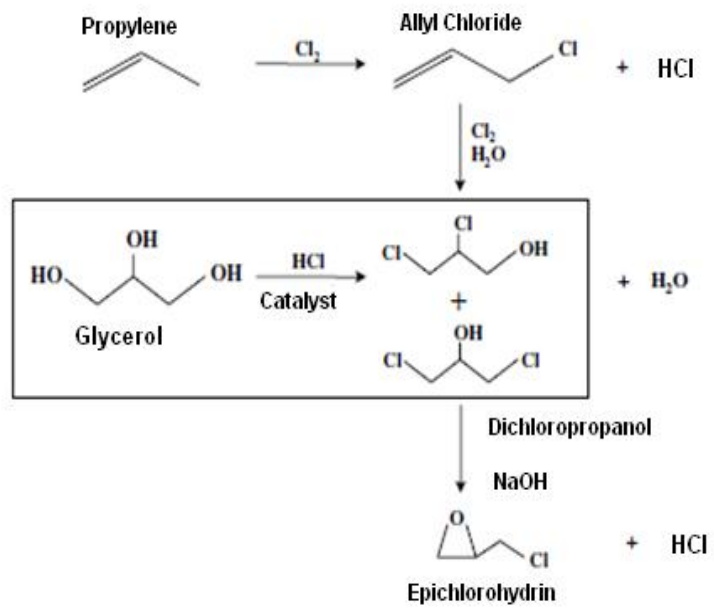

Gambar 1 Sintesa Epiklorohidrin melalui jalur alil klorida dan jalur dikloropropanol

(Lee $d k k, 2008$ )

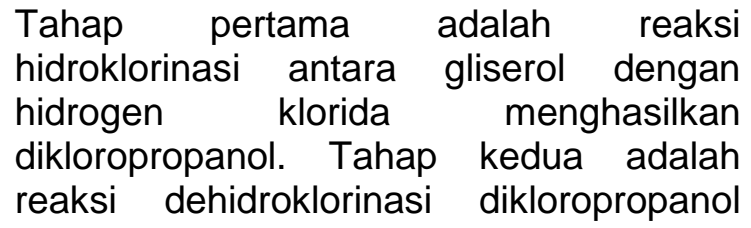

dan larutan basa menghasilkan epiklorohidrin. Kajian kinetika pada tulisan ini fokus pada reaksi tahap kedua dimana larutan basa yang digunakan adalah sodium hidroksida 5 M. Sintesa epiklorohidrin melalui jalur alil klorida dan dikloropropanol disajikan pada Gambar 1.

Sebelumnya, (Ma,L., dkk, 2007) telah melakukan kajian kinetika reaksi dehidroklorinasi dikloropropanol dan kalsium hidroksida pada temperatur 50 $80^{\circ} \mathrm{C}$. Larutan basa ditambahkan dengan rasio mol 1:1 terhadap dikloropropanol. Menurut Ma dkk, model kinetika reaksi mengikuti persamaan reaksi orde dua sebagai berikut:

$$
-r_{\theta p y}=-\frac{a[D C P]}{d t}=k[D C P]^{[}\left[O H^{-}\right]^{\beta} \ldots(1)
$$

Dimana [DCP $]$ dan $\left[\mathrm{OH}^{-}\right]$adalah konsentrasi dikloropropanol dan kalsium hidroksida berturut-turut.

Namun demikian, berdasarkan kajian simulasi terdahulu yang dilakukan Herliati dkk (Herliati, 2011), didapat bahwa larutan sodium hidroksida memberikan hasil yang lebih baik dibandingkan kalsium hidroksida. Untuk itu pada kajian ini, digunakan larutan sodium. Berdasarkan kajian sebelumnya juga telah dilakukan simulasi dan diamati pengaruh mol rasio terhadap laju reaksi. Hasil simulasi merekomendasikan rasio mol sodium hidroksida 5:1 terhadap dikloropropanol (Herliati dkk, 2011).

Sesuai dengan azas Le'Chatelier, salah satu cara untuk mendorong reaksi ke arah pembentukan adalah dengan melebihkan salah satu reaktan. Oleh karena sodium hidroksida jauh lebih murah dibandingkan dengan reaktan yang lainnya, maka pada kajian ini larutan sodium hidroksida dibuat berlebih.

Dengan konsentrasi hidroksida dibuat berlebih, maka $\left[\mathrm{OH}^{-}\right]$diasumsikan tidak berpangaruh terhadap laju reaksi dengan kata lain memiliki orde nol, sehingga persamaan laju reaksi dapat dinyatakan dalam model kinetika orde satu semu sebagai berikut, teori ini dapat dijumpai pada literatur (Laidler, 1987) : 
$-r_{\theta p y}=-\frac{d[D C P\}}{d t}=k[D C P]$

Pada kajian ini, 2,3-Dikloropropanol sebagai isomer dari 1,3-Dikloropropanol, tidak diperhitungkan. Hal ini dimungkinkan karena digunakan 1,3-Dikloropropanol murni yaitu (99.9\%). Selain itu, berdasarkan hasil pengamatan yang dilakukan oleh Ma dkk (2007), reaktifitas 1,3-Dikloropropanol jauh lebih tinggi dbandingkan dengan isomernya 2,3Dikloropropanol. Hal ini dijelaskan melalui efek induksi dan efek ruang seperti diperlihatkan pada Gambar 2. Dalam molekul struktur, untuk senyawa-senyawa alkil halogen, sulit bagi gugus hidroksil untuk menyerang 2-C pada 2,3Dikloropropanol. Hal yang demikian disebut dengan steric hindrance (Ma dkk., 2007).

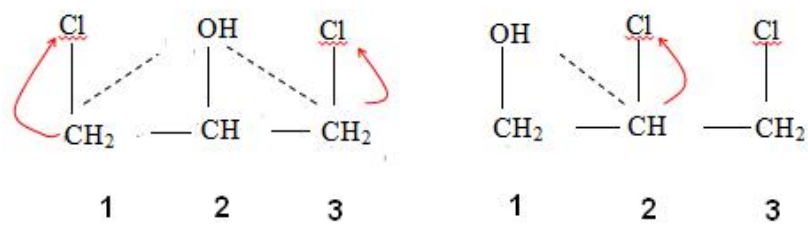

\section{Gambar. 2 efek ruang dan induksi gugus hiroksil (Ma dkk., 2007)}

Penentuan konstanta laju reaksi sangat bergantung pada orde reaksi. Orde reaksi yang diperoleh dari data eksperimen dikatakan valid jika fungsi persamaan laju reaksi merupakan suatu garis lurus, dan nilai konstanta laju reaksi adalah slope dari persamaan garis lurus tersebut.

\section{METODE}

Reaksi dilangsungkan di dalam sebuah labu leher tiga (250-ml), yang dipanaskan dengan hot plate, dilengkapi dengan termometer, sebuah sampling port dan sebuah kondensor. Kondensor dihubungkan dengan sebuah penampung. Oil bath digunakan untuk mengontrol temperatur reaktor. Sebuah pengaduk magnet digunakan untuk membuat campuran di dalam reaktor menjadi homogen. Gambar 1 memperlihatkan setup alat eksperimen. Ditimbang sebanyak 17,4 g dikloropropanol, 11,5 g NaOH, dan
129,6 $\mathrm{ml} \mathrm{H} \mathrm{H}_{2} \mathrm{O}(\mathrm{NaOH} 5 \mathrm{M})$. Semua reaktan dicampur di dalam reaktor lalu campuran dipanaskan. Setelah suhu reaksi mencapai $50^{\circ} \mathrm{C}$, sampel ditarik pada menit ke 5, 10, 15 dan 20. Sampel sebanyak 1 $\mathrm{ml}$ lalu diletakkan di dalam vial bertutup dan berwarna gelap. Sampel disimpan di dalam lemari pendingin sebelum di analisa dalam rangka mencegah reaksi hidrolisis dari epiklorohidrin (Ma, J. dkk, 2007). Selanjutnya ekperimen dilanjutkan untuk suhu reaksi 60,70 dan $80^{\circ} \mathrm{C}$ dengan prosedur yang sama.

Sampel-sampel ini lalu dianalisa secara kuantitatif. Analisa menggunakan GC-MS dengan spesifikasi HP-WAX kolom kapiler dengan panjang 25 meter, diameter 0,25 $\mathrm{mm}$ dan tebal film 0,25 m. Metode yang digunakan adalah, gas pembawa menggunakan helium; temperatur injektor $=250{ }^{\circ} \mathrm{C}$; temperatur detektor $=230{ }^{\circ} \mathrm{C}$. Sebelum diinjeksikan, sampel dilarutkan ke dalam metanol dengan perbandingan $1: 20$. Volume sampel yang diinjeksikan adalah $1 \mu \mathrm{L}$.

Kolom gas kromatografi yang dijelaskan di atas dapat digunakan untuk mendeteksi epiklorohidrin dan dikloropropanol, metode ini mengacu pada apa yang pernah dilakukan oleh (Vali dkk, 2011) dalam mendeteksi kandungan dikloropropanol yang tersisa selama reaksi berlangsung. Sedangkan untuk mengetahui kandungan $\left[\mathrm{OH}^{-}\right]$dilakukan metode titrasi dengan asam (Ma, J. dkk, 2007).

\section{HASIL DAN PEMBAHASAN}

Data hasil analisa dikloropropanol yang tersisa selama reaksi berlangsung pada berbagai suhu yaitu $50-80^{\circ} \mathrm{C}$ dapat dilihat pada Tabel 1. Penarikan sampel dilakukan pada interval waktu 5, 10, 15 dan 20 menit. Konsentrasi mula-mula dikloropropanol dibuat sama pada setiap suhu yaitu 0,5195 molar. Khusus pada suhu reaksi $80^{\circ} \mathrm{C}$ terlihat bahwa pada waktu reaksi 20 menit tidak terdeteksi ada dikloropropanol yang tersisa. Hal ini dapat dijelaskan bahwa kenaikan suhu dapat meningkatkan nilai konstanta laju reaksi sehingga reaksi menjadi lebih cepat seperti diperlihatkan pada Tabel 2. Namun 
demikian tidak berarti laju reaksi yang cepat juga memberikan hasil yang baik karena ada kemungkinan pada suhu di atas $70^{\circ} \mathrm{C}$ memicu terjadi reaksi hidrolisa yang dapat memperkecil yield dari epiklorohidrin sebagai produk ( $\mathrm{Ma} \mathrm{dkk}$, 2007).

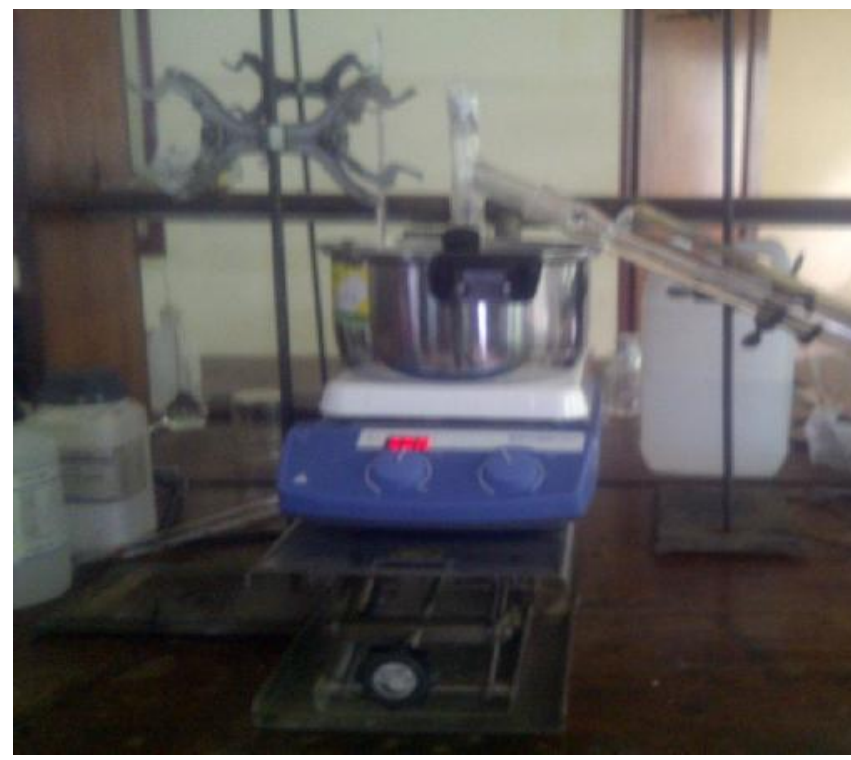

Gambar 3. Rangkaian Alat eksperimen

Tabel 1. Hasil Analisa Dikloropropanol

\begin{tabular}{crccc}
\hline Waktu & \multicolumn{5}{c}{ [DCP] pada berbagai T } \\
\cline { 2 - 6 } (Menit) & $50^{\circ} \mathrm{C}$ & $60^{\circ} \mathrm{C}$ & $70^{\circ} \mathrm{C}$ & $80^{\circ} \mathrm{C}$ \\
\hline \multirow{4}{*}{0} & 0,519 & 0,519 & 0,519 & 0,519 \\
& 5 & 5 & 5 & 5 \\
5 & 0,338 & 0,212 & 0,269 & 0,055 \\
& 3 & 0 & 7 & 6 \\
10 & 0,233 & 0,104 & 0,157 & 0,009 \\
& 4 & 7 & 8 & 6 \\
15 & 0,166 & 0,055 & 0,097 & 0,005 \\
5 & 3 & 4 & 3 \\
20 & 0,121 & 0,030 & 0,061 \\
& 8 & 2 & 9 & $*$ \\
\hline \multicolumn{5}{c}{ *) tidak terdeteksi } \\
\end{tabular}

Tabel 2. Nilai k pada berbagai suhu

\begin{tabular}{rc}
\hline Suhu $\left({ }^{\circ} \mathrm{C}\right)$ & $\mathrm{k}$ \\
\hline 50 & 0.0056 \\
60 & 0.008 \\
70 & 0.012 \\
80 & 0.021 \\
\hline
\end{tabular}

Dalam menentukan konstanta laju reaksi $\mathrm{k}$, sangat bergantung kepada orde reaksi. Data eksperimen pada Tabel 1 kemudian diplot antara waktu reaksi dengan $\ln [D C P]_{0}-\ln [D C P]$ untuk dugaan orde 1 atau plot waktu reaksi dengan 1/[DCP] $1 /[D C P]_{0}$ untuk orde 2 . Jika fungsi persamaan laju berupa garis lurus, maka dugaan orde reaksi dapat diterima. Selanjutnya nilai konstanta laju reaksi dapat ditentukan dengan persamaan (3) dan (4). Persamaan (3) digunakan untuk reaksi orde satu dan persamaan (4) jika reaksi or

$\ln \left[1,3-D x t h \|_{0}-\ln [1,3-D C P]=k t .(3)\right.$ $1 /\left[1,3-v(H]_{0}-1 /\left[1,3-D C P_{0}\right]=k t(4)\right.$ Pada kajian ini dugaan orde satu dapat diterima. Seperti dapat di lihat pada Gambar 4, plot waktu reaksi dengan $\ln [D C P]_{0}-\ln [D C P]$ merupakan sebuah garis lurus dengan nilai koefisien korelasi, $R^{2}>0,99$. Sementara, nilai konstanta laju persamaan garis lurus pada masingmasing temperatur. Selanjutnya nilai $k$ untuk masing-masing temperatur pada variasi $50,60,70$ dan $80^{\circ} \mathrm{C}$, dapat dilihat pada Tabel 2. Nilai $k$ sebagai fungsi temperatur dapat dijelaskan dalam persamaan Arrhenius sebagai berikut (Smith, 2010) :

$$
\ln k=\ln A-\frac{E a}{K T}
$$

Dimana A adalah faktor frekuensi atau faktor tumbukan antar reaktan yang bereaksi, $E_{a}$ adalah energi aktivasi, $R$ adalah konstanta gas ideal (8.314 $\mathrm{J} \mathrm{mol}^{-1}$ $\left.\mathrm{K}^{-1}\right)$, dan $\mathrm{T}$ adalah temperatur absolut yang dinyatakan dengan satuan Kelvin (K). Energi aktivasi diperoleh dengan mengalikan Nilai negatif slope dari plot $\ln (\mathrm{k})$ vs $1 / \mathrm{T} \times 1000$ dengan konstanta gas, R. Sementara nilai $A$ diperoleh dari nilai eksponensial y-intersep. Kedua nilai $A$ dan $\mathrm{E}_{\mathrm{a}}$ merupakan parameter kinetika yang sangat berguna karena dapat digunakan untuk menentukan nilai konstanta laju 


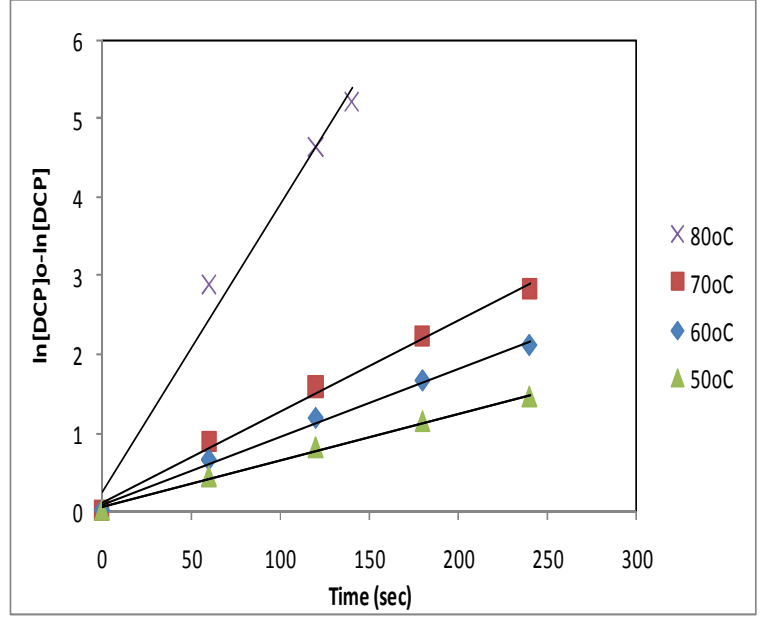

Gambar 4. Model kinetika orde 1 semu untuk dehidroklorinasi DCP dan $\mathrm{NaOH}$

reaksi pada temperatur yang lain. Plot In (k) vs $1 / \mathrm{T} \times 1000$ dapat dilihat pada Gambar 5.

Energi aktivasi yang diperoleh adalah 38.8 $\mathrm{kJ} / \mathrm{mol}$ dan faktor frekuensi, A adalah 1.62 $x 10^{7} \mathrm{sec}^{-1}$. Sementara itu, Ma,L., dkk, 2007, melaporkan nilai $E_{a}$ dan $A \quad 49.18$ $\mathrm{kJ} / \mathrm{mol}$ dan $10^{7}$ det $^{-1}$ berturut-turut dimana menggunakan larutan basa $\mathrm{Ca}(\mathrm{OH})_{2}$. Energi aktivasi, $E_{a}$, difahami sebagai energi minimal untuk berlangsungnya sebuah reaksi atau sering disebut potential barrier. Sebuah reaksi kimia akan berlangsung jika energi reaksi sama atau lebih besar dari energi aktivasi. Dengan kata lain, energi aktivasi yang lebih rendah akan membuat reaksi berlangsung lebih cepat. Persamaan Arrhenius, $k=A e^{\frac{-E a}{R T}}$, memperlihatkan bahwa ketika energi aktivasi lebih kecil, maka nilai $\mathrm{k}$ akan lebih besar yang berakibat reaksi menjadi lebih cepat. Pada kajian ini, diperoleh energi aktivasi yang sedikit lebih rendah dibandingkan dengan peneliti terdahulu.

Oleh karena nilai $E_{a}$ dan $A$ pada rentang temperatur $50-80^{\circ} \mathrm{C}$ telah diperoleh, selanjutnya persamaan umum laju reaksi dehidroklorinasi dikloropropanol dengan larutan sodium hidroksida dapat dinyatakan sebagai berikut:

$-r=1,62 \times 10^{7} e^{\frac{-38,8}{8,314 t}[D C P]}$

Gambar 6 memperlihatkan nilai konstanta laju reaksi yang meningat secara eksponensial dengan meningkatnya suhu

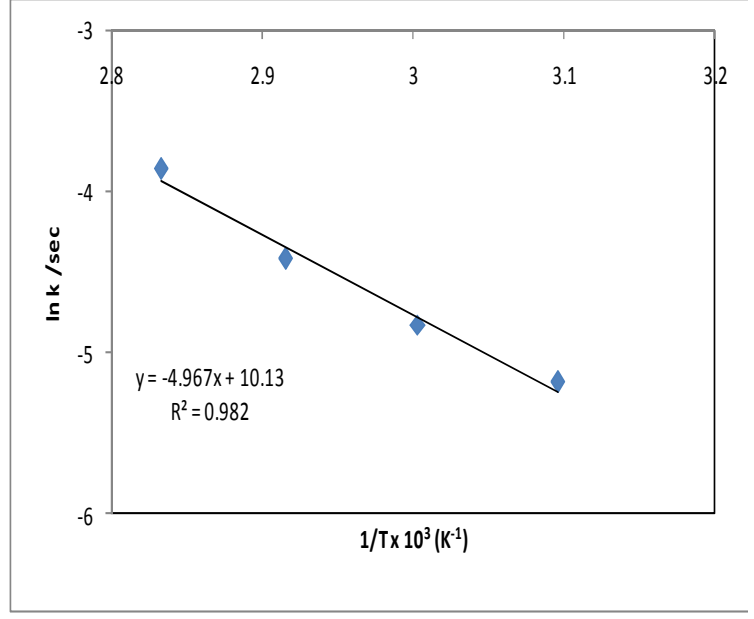

Gambar 5. Plot In (k) vs 1/T untuk reaksi
dehidroklorinasi

reaksi. Ini dapat difahami bahwa sesuai dengan hukum kinetika reaksi bahwa kenaikan suhu akan meningkatkan laju reaksi secara eksponensal yag ditandai meningkatnya nilai konstanta laju reaksi.

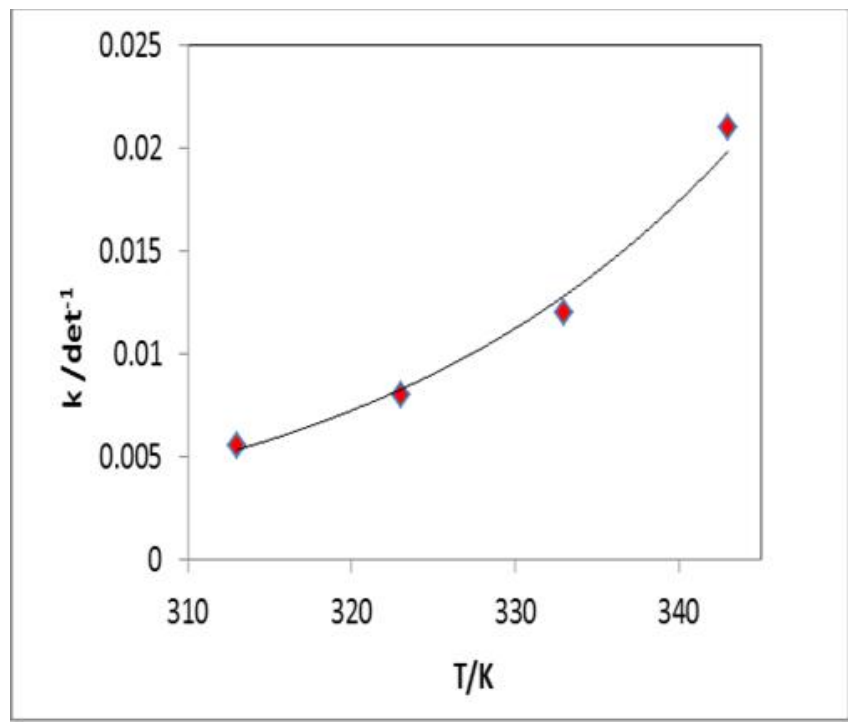

Gambar 6 Pengaruh kenaikan suhu reaksi terhadap nilai konstanta laju reaksi $k$.

\section{SIMPULAN DAN SARAN}

Telah dilakukan kajian kinetika reaksi dehidroklorinasi dikloropropanol dan larutan sodium hidroksida menghasilkan epiklorohidrin. Reaksi berlangsung pada tekanan atmosfir dengan ekses larutan sodium hidroksida pada kisaran temperatur $50-80^{\circ} \mathrm{C}$. Plot waktu reaksi 
terhadap $\ln [\mathrm{DCP}]_{0} \quad-\quad \ln [\mathrm{DCP}]$ menghasilkan persamaan garis lurus, ini memberikan kesimpulan bahwa reaksi berlangsung mengikuti model kinetika orde 1. Pada kajian ini, diperoleh energi aktivasi, $\mathrm{E}_{\mathrm{a}}$, sebesar $38.8 \mathrm{~kJ} / \mathrm{mol}$ dan faktor pre-exponential $A$ sebesar $1.62 \mathrm{x}$ $10^{7} \operatorname{det}^{-1}$. Hasil yang diperoleh ini sedikit lebih baik dibandingkan dengan peneliti terdahulu dimana menggunakan larutan basa kalsium hidroksida dimana nilai energi aktivasi, $E_{a}$ dan faktor preexponensial, A yang diperoleh berturutturut adalah sebesar $49,18 \mathrm{~kJ} / \mathrm{mol}$ dan $10^{7}$ det $^{-1}$. Selanjutnya perlu dilakukan percobaan dengan larutan basa yang lain seperti $\mathrm{Ba}(\mathrm{OH})_{2}$.

\section{DAFTAR PUSTAKA}

Bijsterbosch, J.W., Kerkhof, F.P.J.M, Clean technology in the production of epichlorohydrin. Journal Cleaner Product 2 (1994) 181-184.

Nagato, N., Mori, H., Maki, K., Ishioka, R., Process for production of epichlorohydrin, Pat. US 4,634,784, 1987

Siano, D., Santacesaria, Fiandra, E., Tesser, V., Di Nuzzi, Di Serio, Nastasi, M., Process for the production of alpha, gammadichlorohydrin from glycerin and hydrochloric acid. WIPO: WO 111810 A2, 2006

Santacesaria, E., Tesser, R., M.D. Serio, L. Casale, D. Verde, New process for producing epichlorohydrin via glycerol chlorination, Ind. Eng. Chem. Res. 49 (2010) 964-970.

L. Ma, J.W. Zhu, X.Q. Yuan, Q. Yue, Synthesis of Epichlorohydrin From Dichloropropanol: Kinetic Aspects of the Process, Chemical Engineering Research and Design 85 (2007) 1580-1585.

Shaik Jafer Vali, Raveendra B.Ganduri1 and Shakil S Sait, Estimation of epichlorohydrin content in pharmaceutical drug substances by capillary gas chromatography with flame ionisation detection, Chem. Pharm. Res., 3 (2011): 392-399

Zhang, J.S., Lu, Y.C., Jin, Q.R., Wang, K., Luo, G.S., Determination of kinetic parameters of dehydrochlorination of dichloropropanol in a microreactor, Chemical Engineering Journal 203 (2012) 142-147.

Smith, J.M, Chemical Engineering Kinetic, $5^{\text {rd }}$ ed., McGraw Hill International Edition, Singapore, 2010

Krafft, P., Gilbeau, P., Gossenlin, B. and Claessens, S., Process for producing dichloropropanlol from glycerol-the glycerol coming eventually from the conversion of animal fats in the manufacture of biodiesel[P], SOLVAY, WO/2005/054167,7-10, 2005

Laidler, K.J., Chemical Kinetics, 3rd edition, 42 (Harper \& Row, New York, USA), 1987 